UDK 351.78:004

https://doi.org/10.18485/fb_ic4hs.2018.3

\title{
HOW HUMAN SECURITY COULD BE A BENEFICIARY OF INFORMATION AND COMMUNICATIONS TECHNOLOGY
}

\author{
Ivica Lj. ĐORĐEVIĆ*, Ozren DŽIGURSKI**
}

\begin{abstract}
The invention and application of new technologies have always been important development triggers and indicators. Today, the results of technological progress, among others, mostly depend on the structure and efficiency of modern communication tools. Obviously, in our globalized world, the availability and use of information and communications technologies (ICTs), in addition to the positive effects, is also a potential source of risk for their users. In addition to great development potential of the ICTs, with appropriate access, they can contribute to raising the level of security of people in unstable regions and vulnerable social groups.

The potential of information and communications technologies to support economic development is widely recognized. On the one hand, industrial technologies through economic growth influence the increase and pollution of the environment, and on the other hand, the ICT can increase the efficiency of production processes and business organization by reducing the negative effects of economic activities. For this reason, many international and state institutions in their activities and documents promote the need to build a more humane environment - an inclusive, open and development oriented society in which everyone can create, access, use and participate in the exchange of information and knowledge.

Threats to citizens' safety due to the omnipresence of the ICTs are mostly related to the threat to individual human rights, cyber threats, identity theft, hate speech, child pornography, racism, blocking and filtering of the Internet, misuse of personal data, etc. On the other hand, the protection and security of citizens as members of the information society is predominantly based on directives, recommendations and various initiatives. In addition, technical means of protection, which are realized through commercial offers by certain specialized companies, are available to a certain extent.

This paper shows that in addition to various types of threats and inadequate protection, there are opportunities and resources that can raise the level of security of citizens as members of the emerging global information society. To this end, benefits are shown in different domains - the
\end{abstract}

\footnotetext{
* Associate Professor, PhD, University of Belgrade Faculty of Security Studies, djivica@gmail.com

** Retired Associate Professor, PhD, University of Belgrade Faculty of Security Studies, odzigurski@gmail.com
} 
dimensions of human security (HS), with an emphasis on the economic sphere, upon which depends the situation in other dimensions of the HS to a certain extent.

Finally, some informational and technical tools that can be found in the field of HS are presented: information systems, networks, databases, mobile and other relevant IC technologies.

Keywords: human security: threat, protection, benefits; information and communications technologies

\section{INTRODUCTION}

The potential of the ICT-driven changes induces different reactions in humans. Many are afraid of the negative effects of the spontaneous spread of the ICT as well as of its speed, that is, the comprehensiveness of change. The unevenness of spreading positive effects endangers not only individual existence but also community stability (from local to global). The positive effects of the ICT depend on the ability to anticipate the process and adapt the institutional mechanisms to new tendencies. The problem of the modern world is that the analyses are mainly limited to the growth of the average income per capita and the amount of realized profit as the most common indicators on the basis of which the effects of global processes are evaluated. However, growth often does not mean development, but the deepening of the gap between the poor and the rich, that is, the winners and losers of global processes.

Security aspects of the ICT are usually analysed in the context of human rights violations and privacy while neglecting a rather wide range of other effects on citizens' safety. There are two main directions in the analysis of the effects of the ICT: a non-critical relationship that glorifies positive effects as opposed to the emphasis on negative aspects of the ICT and underestimation of the potential of positive changes in the wake of technological development. The truth is, as usually, somewhere in between. Undoubtedly, there are possibilities for positive changes based on the application of the ICT in practice, however, the impact of the ICT on socio-economic flows depends on the degree of control of institutions over the computerization of human activities. The domination of the monopoly and the financial power arising from this position undermines the ultimate impact of the ICT on the quality of life of people of the modern era.

Due to its holistic approach based on the seven-dimensional conceptual model, the concept of human security (HS) enables a qualitative analysis of the process and an insight into the impact of the ICT on the quality of life of modern man and their community. The ICT is all-embracing and its impact on changes in all HS segments can be identified: starting from its application in the economic sphere where the automation of production activities and service provision is increasingly present, through a healthcare system that acquires new tools and procedures based on the ICT to its influence on political systems and democratic processes that obtain new forms.

\section{THE CONCEPT OF HUMAN SECURITY AS AN ANALYTICAL FRAMEWORK}

Since the fall of the Berlin Wall, contradictory processes have been taking place in the countries of former Eastern bloc. The so-called transitional countries exposed to the processes of initial capital accumulation have experienced a drastic fall in the quality of 
life of their citizens. Instead of the expected progress, we have witnessed a regression in every way. The dysfunction of institutions and their exploitation for the interests of the owners of large-scale capital from abroad and local tycoons (former communist apparatchiks) have caused the fall in living standards, the increase of the unemployed and the collapse of the then social systems (Đorđević, 2013:71-72).

Recognizing the negative effects of the transition, the United Nation Development Programme (UNDP) experts who participated in the writing of the 1994 Development Report offer the concept of Human Security as an analytical framework that should point to the shortcomings in the functioning of the institutional system in order to improve the quality of life of citizens (UNDP, 1994). The concept is universal and its quality is also reflected in the fact that it is not rigid with conservatively set rules, but is adapted to the conditions that are current and within the focus of the analysis. For example, security challenges in developed countries are associated with anomalies in the functioning of democratic electoral procedures, while in developing countries the biggest security challenge is the lack of food or dysfunctionality of the educational and health system.

It is precisely the insensitivity of the existing system to social differences within developed countries and the specificities of underdeveloped countries that make the gap between the rich and the poor (developed and underdeveloped) deeper without any hope of decreasing it. The HS concept provides an analytical framework that allows the identification of anomalies in the existing system of socio-economic relations. By establishing the parameters on the basis of which we can quantify the quality of life of citizens and classify them into seven dimensions ${ }^{1}$, the concept of HS makes a qualitative shift in the critical attitude towards the current system. The definition of a sevendimensional model allows comparison of the quality of life of people in different countries irrespective of the geographical location and degree of development expressed through classical statistical indicators. Often economic statistics blur the image and do not reflect the real situation. In many analyses, data on economic growth are often mistaken for development, resulting in a wrong perception of current trends. ${ }^{2}$

The HS Syntagm comes with the idea of drawing attention of relevant actors to the need for a critical attitude towards the current system. ${ }^{3}$ Pondering the collapse of the bipolar structure of world power and its impact on the former socialist countries, i.e. developing countries, the UN experts estimated that corrective mechanisms were needed in order to stop the initial negative trends. Security in the title of the concept emphasizes the importance and urgency of the need, and Human is imposed in order to indicate the difference in relation to state security, which has the preservation of territorial integrity and institutions protection in its focus. Of course, here we should emphasize that the

1 The Human Development Report for 1994 provides an overview of the HS concept based on the following seven dimensions: Economic, Food Quality, Health System Status, Ecological Situation, Individual Security, Community Security and the Political System (UNDP, 1994: 24-25).

${ }^{2}$ Growth of statistical indicators does not necessarily mean raising the quality of people's lives. Growth is a quantitative category while development refers to the qualitative aspects of the process.

${ }^{3}$ In this case, the process of securitization (adhering to security content) was used to indicate the importance of the area for the functioning of the system. 
concept of HS is not in conflict with classical state or national security. On the contrary, the idea is to draw attention to the shortcomings of the existing system and to use its mechanisms to protect the interests of citizens living in the area under the control of state institutions. It should also be said that the HS concept cannot take effect in practice without the support security systems such as the military, the police, and intelligence and counter-intelligence systems. A qualitative difference with respect to classical security instruments is only in the approach and institutional control that should put those systems in the function of citizens' interests.

\section{SECURITY OF CITIZENS IN THE CONTEXT OF INFORMATION REVOLUTION}

The omnipresence of the ICT affects each of the HS dimensions, whether the effects will be positive or negative depends primarily on the ability of state institutions to control and direct their application. In this context, we think of a state as a representative of the interests of citizens living on its territory. The first of the effects we are talking about here is the impact on the implementation of democratic procedures that ensure the representativeness of the legislature. The ICT as a tool can be misused for electoral will manipulation, which allows for the establishment of a political order that is inconsistent with the interests of a democratic majority. ${ }^{4}$ At the same time, if there are clearly defined rules with the appropriate system of control and sanctioning, the potential of the ICT can contribute to the greater interest and participation of citizens in election processes, thus ensuring the legitimacy of the system. Unfortunately, as can be seen from the Figure 1, the global trend shows a decrease in the number of citizens who use their voting rights.

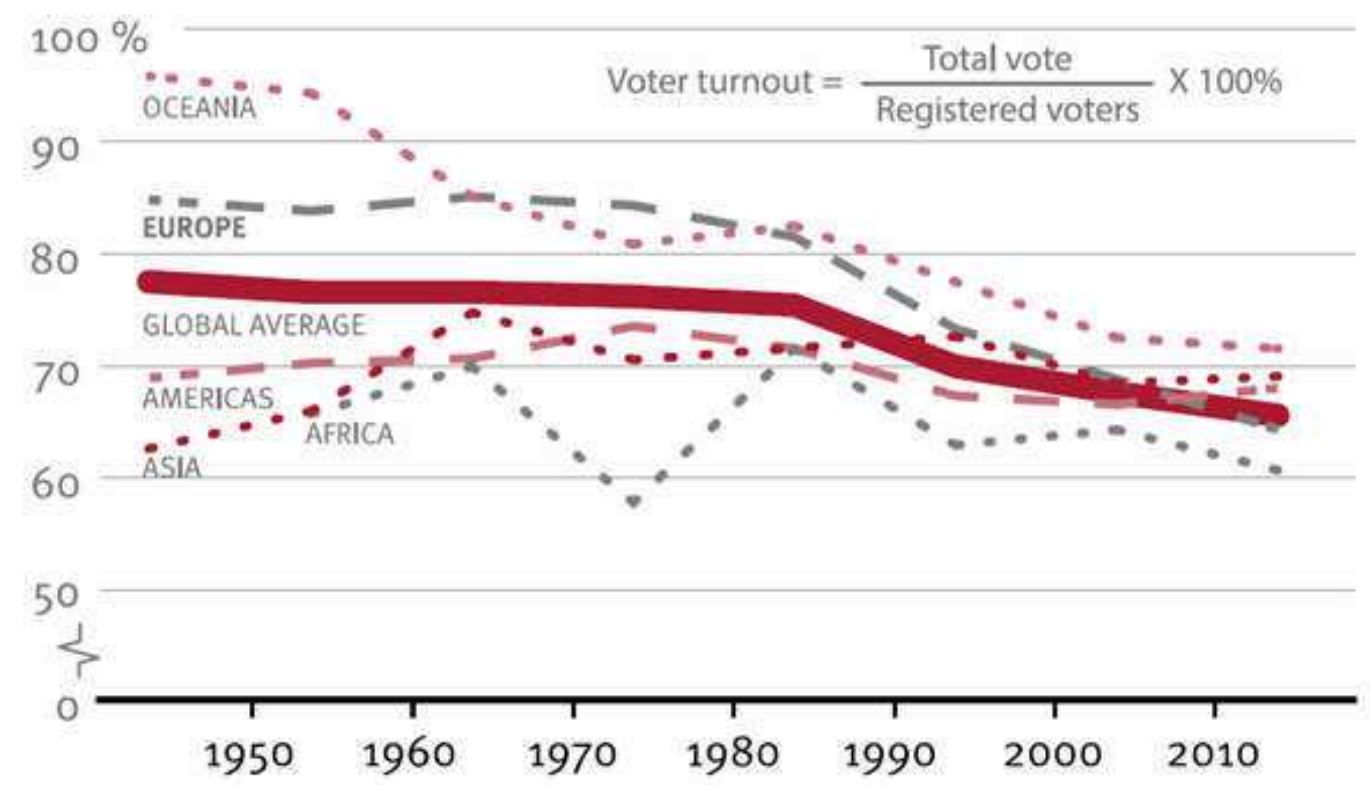

Figure 1. Global voter turnout by region, 1945-2015.

${ }^{4}$ The still-present affair with the Cambridge analyst shows the great power of manipulation with the voting body (Bartlett, 2018: 46-63). 
Source: Abdurashid Solijonov (2016): Voter Turnout Trends around the World, International Institute for Democracy and Electoral Assistance, Stockholm. pg.25. Based on: Voter Turnout Database, www.idea.int/data-tools/data/voter-turnout

Government structure influences all other areas considered important for the quality of life of people living within the jurisdiction of these state institution controlled by the elected citizens' representatives. In the field of food production and distribution, the ICTs have a significant place through the process of organizing and implementing agricultural production, as well as control of the distribution system. In the field of health, there is already a qualitative improvement in the implementation of procedures and diagnostic methods, but there remains considerable scope for manipulation and abuse. Security at the personal and group level, or community, can also be viewed from two aspects. Positive shifts are evident in the area of technical means of surveillance and protection, but at the same time this mechanism can be a source of privacy disruption as well as a tool for conducting criminal activities. Thanks to the Internet, we are nowadays witnesses of the emergence of a global community of people who are gradually becoming aware of the dangers of a global character that can endanger the survival of the living world on the planet. However, due to the lack of regulation and control of activities on the Internet, there is enough space for extremist activities who can manipulate far easier a greater number of people turning them against members of other social groups.

Military systems have become far more efficient thanks to the ICT, however, there is a danger of anomalies in a system that can lead to cataclysm of global proportions. For example, the approach to the use of drones and other automated assets in military operations causing collateral damage, which is a euphemism for human victims in the conduct of combat operations, is utterly ethically questioned.

In the end, not without reason we want to present economic effects that can be interpreted as twofold: as a cause and consequence. Namely, the bulk of practical implementation of the ICT is inspired by the increase in the earnings of company owners and research centres. The effects upon population are extremely controversial because many workers have lost their jobs due to the introduction of robots and automated production lines (see Figure 2.). There is a huge number of people who, instead of the positive effects of the ICT implementation, have become social welfare beneficiaries and have been declared a surplus due to their inability to adapt to new trends. Generations that are no longer able to re-qualify for service activities, that is, to become program developers at 50 or more years of age are mostly affected by this process. The effects of the ICT applications in the economic sphere have a significant impact on the political situation, the citizens' attitude to participation in election processes and thus lead to retrograde phenomena. Disenchantment in relation to one's own situation leads to the election of right-wing populists, and endangered citizens become more susceptible to manipulations by electoral headquarters of political actors, which again brings us back to the beginning of a story related to the electoral environment. Data presented in the figures point to the dramatic situation, as the forecasts are such that in some professions there will be no need for human labour in the near future. 


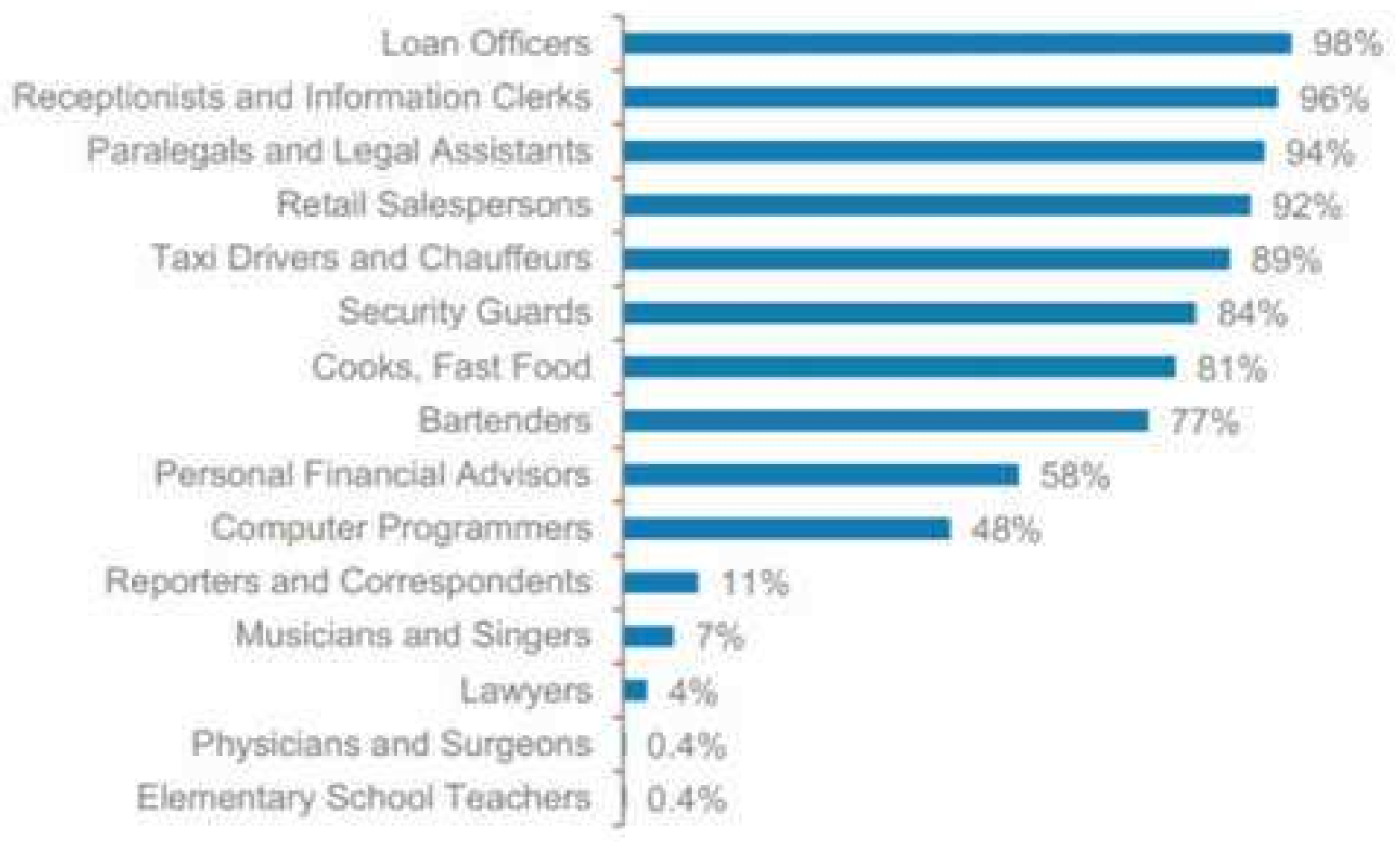

Figure 2. Probability of a job becoming automatable

Reif L. Rafael (2018): A survival guide for The Fourth Industrial Revolution, Davos: World Economic Forum. Based on: University of Oxford, Morgan Stanley. https://www.weforum.org/agenda/2018/01/the-fourth-industrial-revolution-a-survival-guide/

\section{SECURITY OF PEOPLE IN GLOBALIZATION CONDITIONS}

The ICT has dramatically accelerated the process of globalization of human activities. There has always been a tendency to connect known space into one whole. World imperators have always wanted to be at the forefront of a global empire, religious leaders have dreamed of the universality of their religions, and philosophers have had a tendency toward cosmopolitanism. Only with the development of the ICT have the conditions for the establishment of global business and social networks been created, which has both its advantages and disadvantage i.e. risks the world has not found a response to yet.

The expansion of human activities beyond the borders of national states entails certain risks and threats that are not entirely new, but are gaining new dimensions. Due to the fact that global practice has not received appropriate institutional attention and response, phenomena such as privacy threats, the spread of extremism and various criminal activities are gaining in their severity, as the range of actions of national institutions is limited to the area within state borders (Kamei, 2012). Thanks to the use of the ICT, criminal organizations spread their activities across national borders using their porosity. Using the liberalization of cross-border traffic, criminal and extremist organizations create collaborative networks across the entire planet.

The lack of institutional response to changing environment and current global practice have become serious also due to the fact that national states have been their power under 
enormous pressure by large capital whose exponents are transnational companies (TNC). The monopolization of economic activities in global proportions shifts the power from state institutions to the hands of large capital managers. Driven exclusively by maximizing profits as the only benchmark of success, the TNCs delegitimize the political system and institutional levers of government are being exploited for their own needs. Imperative growth of profit rates makes the classical mechanisms of controlling cross-border human trafficking, goods and finances unsustainable. In order to remain efficient, long-term and complex procedures are not practiced any more since they slow down the cross-border flow, which creates conditions for intensifying criminal activities such as human trafficking, dangerous substances and narcotics smuggling, and various products that infringe intellectual property rights and pose a danger to users due to poor quality. Financial markets are becoming a major source of economic instability because transfers are no longer related to the needs of the real economy, but are largely driven by stockmarket speculation ${ }^{5}$. The speculations lead to the collapse of large transnational systems, but also to instability at the level of a state, that is, a region and globally. The subject of speculation is not only the shares of corporations, but also the value of national currencies.

Under the pressure of blackmail, the poor and underdeveloped countries agree to lower standards in protecting workers' rights and the environment. Disadvantageous arrangements are being worked out and they break down the standard of the local population, devastate natural assets and resources as well as existing infrastructure. Using the system of TNCs transfer pricing, they avoid liabilities towards local communities, thereby increasing their own profits.

Large fluctuations of people and goods increase the likelihood of global epidemics. The health systems of underdeveloped countries are unable to apply health care standards that have been met in the developed world. There are evident pests that transmit various diseases through container transport, but climate change also creates conditions for the spread of insects and rodent habitats to the northern parts of the planet that have been previously out of their range.

High degree of corruption as a result of the collapse of national institutions leads to the loss of citizens' confidence in such institutions and creates a suitable environment for provoking intolerance towards members of other nations and religions, which significantly affects security within national borders, but also at the regional or global level. The described situation can additionally deteriorate due to the possibilities provided by the ICT, by which the population of developing countries acquires an idealized image of the West that is far from realistic living conditions. At the same time, the Internet becomes a channel that allows fundamentalist organizations to exploit the sense of those being deprived as the losers of globalization and successfully promote their ideas in order to gain new supporters.

\footnotetext{
${ }^{5}$ According to data for 2011 , it is estimated that at least $80 \%$ of transactions in the global capital market are motivated by speculation, that is, only $0.6 \%$ of financial transactions are directly related to trade, production and services. (Andreou, 2013)
} 


\section{POSSIBLE CONTRIBUTION OF THE ICT TO HUMAN SECURITY}

Modern ICT-based technologies have led to dynamic changes that affect human safety. In addition to exacerbating some of the negative phenomena of the ICT, thanks to the use of new techniques and data processing tools, experts can improve their work and, through risk identification, raise the level of security for vulnerable groups. Database creation and data mining raise the level of efficiency of the fight against human trafficking, unsafe migrations, cyber warfare, the use of unmanned aircraft, research in the field of human rights and violence policies. (Latonero and Gold, 2015). The collection and analysis of large amounts of data through advanced searches, pattern recognition and visualization enable the identification of relevant parameters that reveal social relationships and characteristics the very subjects (groups and individuals) that are being monitored are often not aware of.

The information obtained from the analysis of the collected data can play a major role in the decision-making processes that are important for the level of citizen security. New technologies also enable new approaches in policy making and faster than ever intervention in the physical, social and political environment. Organizations and institutions dealing with security issues through the use of advanced foresight techniques can create models for the development of possible conflicts and crisis situations, which makes it possible to make better decisions based on an early warning system.

Below the text we will present several examples of different levels of the ICT application in the field of human security, ranging from standard databases and information systems to the application of artificial intelligence in this field.

\section{Database of HS indexes}

The significance of information tools for human security can be illustrated through an example of a project aimed at determining the indicators for the assessment of the level of human security. Project Human Security Index was realized in the period 2008-2010 and encompassed more than 200 countries and territories. The HSI shows the individual security of citizens in cities, at the state level and globally. The HSI includes the analysis of three main domains: economic, environmental and social in terms of sustainable development, social responsibility and other relevant areas. Due to the number of individual indicators, this project is technically realized in open-source software, which enables the definition of new, modification and reconfiguration of existing indicators and creation of a new composite index HSI. The HSI project is aimed at supporting the use of existing and development of new indicators by analysts and policy makers of urban planning and development in the domain of human security (Hastings, 2011).

\section{Visualization in the domain of HS data}

The efficient application of complex HS indexes can be achieved using the visualization process. Visualization is a large amount of data analysis technique that permits the perception of internal relationships and the perception of different forms of data configurations. Visualization in the field of human security can help analysts, 
in addition to presenting the current state, identify potential problems and threats that can possibly occur.

An example of the use of visualization in the domain of human security can be found in the document: Assessing Human Insecurity Worldwide: The Way to a Human Security Index, (Werthes, 2011). The document displays a multi-dimensional index [Human (In) Security Index], which allows the assessment of appropriate levels of human (non) security. The operationalization process is applied to all dimensions of human security in order to reach the global index and is one of the possible conceptual approaches for analysing the current situation and potential threats in the field of human security. An example of a visual representation of the Global Index of Human Security is presented in Figure 3.

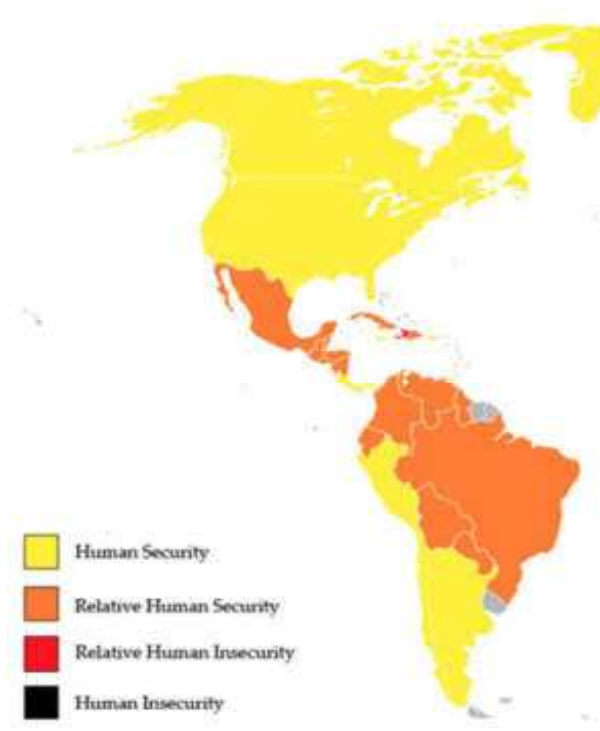

Figure 3: World Map - Human (In)Security

Source: Werthes, S., Heaven C. Vollnhals S. (2011): Assessing Human Insecurity Worldwide: The Way to A Human (In)Security Index. Institute for Development and Peace, University of Duisburg - Essen (INEF - Report 102/2011) pg.40.

\section{HS Networks}

Among numerous applications of the ICT in the field of human security a significant place is given to an activity taking place on the Internet through the development of websites and the creation of networks by institutions and interested groups of citizens. One of the most important networks is the Human Security Network (HSN), whose activity is coordinated by the United Nations.

The Human Security Network consisting of 12 countries aims at promoting the concept of human security as relevant to the creation of national and international policies. Of particular importance is the fact that the activities of the network take place within the United Nations through cooperation with academic institutions and civil society 
organizations. The network was established in 1999 after successful cooperation between Austria, Norway and Canada in order to achieve an international ban on anti-personnel mines. Current members of the Network are: Austria, Chile, Costa Rica, Greece, Ireland, Jordan, Mali, Norway, Panama, Slovenia, Switzerland and Thailand, and South Africa has an observer status. The activity of the network is coordinated by_the Special Representative of the Secretary General for Human Security and the Human Security Unit. (https://www.un.org/humansecurity/), and each year the work of the Network is chaired by one of the network members. The Network's activity is aimed at familiarizing the UN member states with the significance of applying the concept of human security in the work of the United Nations. (Fuentes, 2009).

\section{Human security \& artificial intelligence}

The application of Artificial Intelligence (AI) technology is one of the positive effects of ICT that provides an efficient response in real time to various human security related issues. (Roff, 2017). Achievements in AI's development allow the international community, governments and civil society to anticipate and prevent various forms of threats to human security. AI applications related to the search, classification, and recognition of threat indicators can help analyse correlations and extract content from multiple sources as well as based on large amounts of data. ${ }^{6}$

The potential for AI application is particularly evident in situations such as complex humanitarian crises where there is a combination of the negative effects of political and natural factors. In these situations, data on available resources can be processed and satellite-based real-time monitoring of terrain can be used, overcoming the time constraints for emergency interventions, and thus reducing the number of casualties or material damage. Preventive measures can be taken using the advantages of mobile networks and various media. For example, permanent monitoring of problem areas or environments of companies that can be a source of pollution provides an adequate and timely response in the field of environmental protection.

By combining sensors and video devices to collect information from the environment, AI applications raise security at the individual level, that is, they prevent the endangerment of people in public areas and in their homes. In addition, processing information about persons under judicial supervision of the AI allows for predicting potentially violent behaviour by monitoring their field activities.

In the field of health care, there are many advantages of using AI. The ability of AI to classify and identify medical data and recordings allows the recognition of complex

6 "The new IBM X-Force Threat Management Services uses an artificial intelligence (AI) engine to automate active threat management. The platform compares security incidents against 600,000 historical use cases, and can help automate parts of the threat management process that would typically require human intervention, according to the release. The new Resilient Incident Response Platform can help security analysts orchestrate and automate hundreds of repetitive, complicated response actions that previously required a lot of time. It also offers enterprise-grade integrations out of the box, according to the release, and a drag-and-drop business process management notation workflow engine" (DeNisco Rayome, 2018). 
correlations and the establishment of medical diagnostics much faster and more precisely in relation to a process that depends exclusively on human factors.

A good example of application of AI in the field of human security is a digital food safety information portal that consolidates data from international food agencies, food alert systems, news sources, food manufacturers and social media, into a single access point. For the first time the entire food value chain and any associated health risks in one single place are presented. The service is designed to increase transparency across the food value chain - protecting consumers and the reputation of brands. Internet portal Safefood.ai can be customized to ensure to stay up-to-date with all public food safety risks, relevant to the raw materials and ingredients, covered by supply chains (Selz, 2018).

In the field of economic security, the application of AI in the new economic development paradigm called The Economics of Abundance (Hoeschele, 2010) is interesting. The Economics of Abundance is based on a critique of the current economic system based on the exhaustion of natural resources, which results in devastation of the living environment. The application of the new economic paradigm can be spurred largely by digital communications, using renewable energy sources and efficient means of transport. Companies and institutions that operate on new principles in theory are recognized as software-driven entities. AI's application of management and control in resource exploitation, as well as the achievement of optimum working conditions can significantly contribute to the safety of people.

\section{CONCLUSION}

The security environment that arises with the $4^{\text {te }}$ Industrial Revolution (4IR) drastically differs from the conditions in which an existing institutional model based on national states and the current world order based on the Westphalian agreement emerged. A system based on the achievements of the first industrial revolution is unable to satisfy the needs of modern actors of the new era. It is in the interest of all actors to find a new model of functioning of modern civilization because they are exposed to new risks and threats due to the lack of a global institutional system. In the current circumstances, the power of practical action is on the side of the controllers of large capital, but citizens can still influence the creation of new conditions through the current democratic system. The concept of human security is precisely reminiscent of the obligation of states to protect their citizens.

The concept of human security reminds us that the interests of states and economic entities cannot be protected by endangering the basic human rights. Protection of human rights is a basic premise of the existing UN system and represents an international obligation all countries have to comply with. The undertaken measures in emergency conditions must be in accordance with international conventions and must not jeopardize the human rights of the affected population. To that end, the European Parliament has adopted certain codes of conduct and guidelines for the implementation of human rights obligations when undertaking restrictive and security measures. (Council of Europe, 2002). In the given context, the adoption of the Charter on Human Rights and Principles for the Internet, which is based on the Universal Declaration of Human Rights, provides a comprehensive 
approach to the interpretation of human rights in information societies. (Charter on Human Rights and Principles for the Internet, 2018). The Council of Europe has taken a leading role in the development of guidelines, code of conduct and recommendations on the preservation of public services on the Internet, especially in the context of human rights. (Kettemann, Matthias, 2011).

It should be emphasized that the ICT and AI provide certain opportunities, but do not have ready solutions for all problems in the field of Human Security. Through a multidisciplinary approach, AI can contribute to understanding the process through modelling and replication of cognitive processes. Based on various computer, logical and natural principles, the application of AI can raise the level of efficiency in solving certain security tasks. However, the ICT with the use of AI is not able to completely replace people's decision-making, but it can help achieve the goal of reducing human insecurity by maximizing the positive and reducing the negative effects of applying existing human knowledge. The requirement for positive effects of the ICT implementation is transparent and responsible behaviour in the field of Human Security, which can be followed by strict rules with an appropriate system of controlling their application. Establishing a new global institutional system based on democratic traditions is the only acceptable path to a sustainable global community of people on the planet earth.

\section{REFERENCES}

Andreou, A. (2013). The rise of money trading has made our economy all mud and no brick. The Guardian, Wed 20 Nov. Visited 09.VIII 2018. on: https://www.theguardian.com/commentisfree/2013/nov/20/money-tradingeconomy-foreign-exchange-markets-economy

Bartlett, J. (2018). The People vs. Tech: How the Internet is Killing Democracy. New York: DUTTON.

Bellamy, A. J. (2009). Responsibility to Protect: The Global Effect to End Genocide and Mass Atrocities. Cambridge: Policy Press.

Benedek, W. (2012). Human Security in the Information Society. Human Security Perspectives, Volume 9, Issue 1, 1-14.

Council of Europe (2002). Guidelines On Human Rights And The Fight Against Terrorism, 11 July. Strasbourg.

DeNisco Rayome, A. (2018). How IBM's new cyber tools use AI to make human security pros more effective. TechRepublic, April 16. Visited 19.IX 2018. on: https://www.techrepublic.com/article/how-ibms-new-cyber-tools-use-ai-to-makehuman-security-pros-more-effective/

Đorđević, Lj. I. (2013). Ljudska bezbednost - globalni kontekst i primena u Srbiji. Beograd: Dosije Studio i Institut za uporedno pravo.

Franklin, M., Bodle, R. and Hawtin, D. eds. (2018). Charter on Human Rights and Principles for the Internet. Internet Rights \& Principles Coalition. UN Internet Governance Forum. Visited 19.VIII 2018. on: http://internetrightsandprinciples.org/site/wpcontent/uploads/2018/01/IRPC_english_5thedition.pdf 
Fuentes, C. and Brauch, H. (2009). The Human Security Network: A Global North-South Coalition. Berlin Heidelberg: Springer-Verlag.

Fukuda-Parr, S. (2003). New Threats to Human Security in the Era of Globalization. Journal of Human Development, Vol. 4, No. 2, July.

Hastings, D. A. (2011). Human Security Index: Update and New Release, Visited 19. IX 2018. on: http://www.humansecurityindex.org/wordpress/wpcontent/uploads/2011/03/hsiv2-documentation1.pdf

Hoeschele, W. (2010). The Economics of Abundance: A Political Economy of Freedom, Equity, and Sustainability. Aldershot: Gower Publishing.

International Commission on Intervention and State Sovereignty - ICISS (2001). Responsibility to Protect. Ottawa: International Development Research Centre.

Kamei, K. (2013). Human Security and Globalization. Journal of Poole Gakuin University, Vol. 54, $63-76$.

Kettemann, C. M. (2010). Ensuring Human Rights Online: An Appraisal of Selected Council of Europe Initiatives in the Information Society Sector in 2010. in: Benedek, W.; Benoit-Rohmer F.; Wolfram, K. and Manfred, N. (eds.) (2011). European Yearbook On Human Rights, Vienna: Intersentia. 248-267.

Latonero, M. and Gold, Z. (2015). Data, Human Rights \& Human Security. New York: Data \& Society Research Institute.

Reif, L. R. (2018). A survival guide for The Fourth Industrial Revolution, Davos: World Economic Forum. Visited 19.VIII 2018. on: https://www.weforum.org/agenda/2018/01/the-fourth-industrial-revolution-asurvival-guide/

Roffm, H. (2017). Advancing Human Security through Artificial Intelligence. Research Paper. London: Chatham House, the Royal Institute of International Affairs.

Selz, D. (2018). Launch of Safefood.ai - The world's first AI driven Food Safety Intelligence Service. June 12. Visited 19.VIII 2018. on: https://squirro.com/2018/06/12/launch-safefood-ai-worlds-first-ai-driven-foodsafety-intelligence-service/

UNDP (1994): Human Development Report. New York - Oxford: Oxford University Press.

Werthes, S., Heaven, C. and Vollnhals S. (2011). Assessing Human Insecurity Worldwide:The Way to A Human (In)Security Index, INEF Report 102/2011, Institute for Development and Peace, Universität Duisburg - Essen. 